\title{
Dry Sliding Friction and Wear Studies of Fly Ash Reinforced AA-6351 Metal Matrix Composites
}

\author{
M. Uthayakumar, ${ }^{1}$ S. Thirumalai Kumaran, ${ }^{1}$ and S. Aravindan ${ }^{2}$ \\ ${ }^{1}$ Department of Mechanical Engineering, Kalasalingam University, Krishnankoil, Tamil Nadu 626 126, India \\ ${ }^{2}$ Department of Mechanical Engineering, Indian Institute of Technology, New Delhi 110 016, India \\ Correspondence should be addressed to M. Uthayakumar; uthaykumar@gmail.com
}

Received 27 September 2012; Revised 28 December 2012; Accepted 30 December 2012

Academic Editor: Huseyin Çimenoğlu

Copyright (c) 2013 M. Uthayakumar et al. This is an open access article distributed under the Creative Commons Attribution License, which permits unrestricted use, distribution, and reproduction in any medium, provided the original work is properly cited.

\begin{abstract}
Fly ash particles are potentially used in metal matrix composites due to their low cost, low density, and availability in large quantities as waste by-products in thermal power plants. This study describes multifactor-based experiments that were applied to research and investigation on dry sliding wear system of stir-cast aluminum alloy 6351 with 5, 10, and $15 \mathrm{wt}$.\% fly ash reinforced metal matrix composites (MMCs). The effects of parameters such as load, sliding speed, and percentage of fly ash on the sliding wear, specific wear rate, and friction coefficient were analyzed using Grey relational analysis on a pin-on-disc machine. Analysis of variance (ANOVA) was also employed to investigate which design parameters significantly affect the wear behavior of the composite. The results showed that the applied load exerted the greatest effect on the dry sliding wear followed by the sliding velocity.
\end{abstract}

\section{Introduction}

Metal matrix composites (MMCs) have received substantial attention due to their reputation as stronger, stiffer, lighter, and excellent wear properties over the monolithic alloys [13]. Though MMCs possess superior properties, they have not been widely applied due to the complexity of fabrication [4]. The conventional stir casting is an attractive processing method for fabrication, as it is relatively inexpensive and offers wide selection of materials and processing conditions. Stir casting offers better matrix particle bonding due to stirring action of particles into melts [5].

Wear is one of the most commonly encountered industrial problems, leading to frequent replacement of components, particularly abrasion. Abrasive wear occurs when hard particles or asperities penetrate a softer surface and displace material in the form of elongated chips and slivers [6]. Extensive studies on the tribological characteristics of aluminum MMCs containing various reinforcements such as silicon carbide, alumina, and short steel fiber are already done by researchers [7-9]. The variables such as composition of the matrix, particle distribution, and interface between the particles and the matrix affect the tribological behavior of metal matrix composites. These conditions include the type of countersurface, applied load, sliding speed, contact area, geometry, and environment [10]. The principle tribological parameters such as applied load [11-13], sliding speed [14, 15], and percentage of fly ash control the friction and wear performance. Fly ash is one of the residues generated in the combustion of coal. The addition of fly ash leads to the increase in wear resistance, hardness, elastic modulus and proof stress compared to unreinforced alloy. The fly ash particle size and its volume fraction also significantly affect the wear and friction properties of composites $[16,17]$.

The aim of the present study is to investigate the dry sliding wear of stir cast AA 6351 with 5, 10, and 15 wt.\% fly ash reinforced MMCs, using a pin-on-disc type of wear machine. Furthermore, ANOVA was employed to investigate which design parameters significantly affect the wear behavior of the composite. Confirmation test was also conducted to verify the improvement of the quality characteristic using optimal levels of the design parameters. 
TABLE 1: Elements of AA-6351 and its weight (\%).

\begin{tabular}{lcccc}
\hline Elements & $\mathrm{Al}$ & $\mathrm{Si}$ & $\mathrm{Mn}$ & $\mathrm{Mg}$ \\
\hline Weight (\%) & 97.8 & 1.0 & 0.6 & 0.6 \\
\hline
\end{tabular}

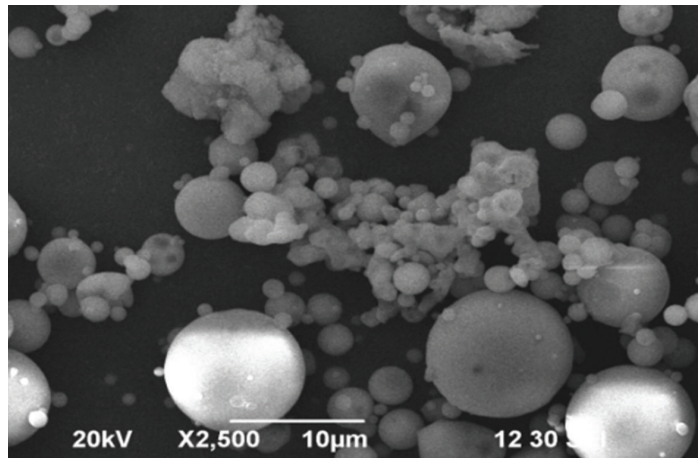

Figure 1: Micrograph of fly ash.

\section{Materials and Experimental Procedures}

2.1. Raw Material Description and Its Composition. Aluminum alloy 6351 is used in heavy engineering applications due to its strength, bearing capacity, ease of workability, and weldability. It is also used in building ship, column, chimney, rod, mould, pipe, tube, vehicle, bridge, crane, and roof [18]. The elements of aluminum alloy 6351 and the weight in $\%$ are tabulated in Table 1.

Fly ash is an industrial by-product recovered from the flue gas of coal burning electric power plants. Fly ash particles are mostly spherical in shape. The fly ash is collected from Tuticorin thermal power station, India, with an average particle size of 2-10 microns, and its typical micrograph is presented in Figure 1.

2.2. Fabrication of Composite. AA-6351 with 5, 10, and $15 \mathrm{wt} . \%$ fly ash reinforced MMCs are prepared by stir casting process. The melting was carried out in a resistance furnace. The fly ash particles were preheated on an open hearth furnace for one hour to remove the moisture. Scraps of AA 6351 were preheated at $450^{\circ} \mathrm{C}$ for 3 to $4 \mathrm{~h}$ before melting. The preheated aluminum scraps were first heated above the liquidus temperature to melt them completely. They were then slightly cooled below the liquidus to maintain the slurry in the semisolid state. This procedure has been adopted while stir-casting aluminum composites $[19,20]$. Typical specimen is shown in Figure 2.

2.3. Wear Tests. The pin-on-disc machine was used to evaluate the friction and wear response to the sliding contact surface of the specimens as shown in Figure 3. Tests were conducted under dry conditions as per ASTM G99-95 standards. The pin was initially cleaned with acetone and weighed accurately using a digital electronic balance. The test was carried out by applying load $(9.81,19.62$, and $29.43 \mathrm{~N}$ ) and run for a constant sliding distance $(3000 \mathrm{~m})$ at different sliding velocities $(1,2$, and $3 \mathrm{~m} / \mathrm{s})$. The disc material was made

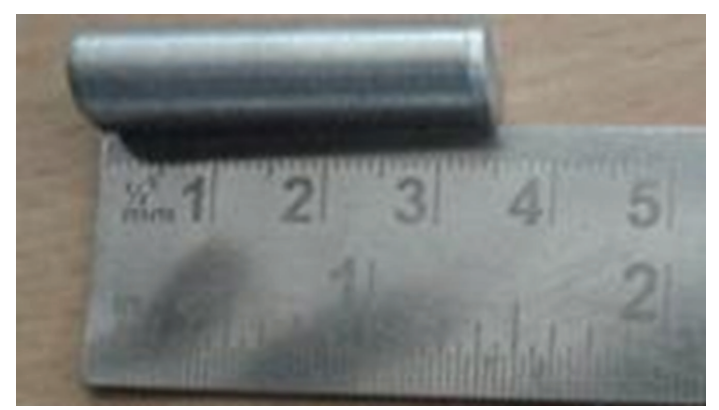

FIGURE 2: Typical specimen of AA 6351-fly ash reinforced MMC.

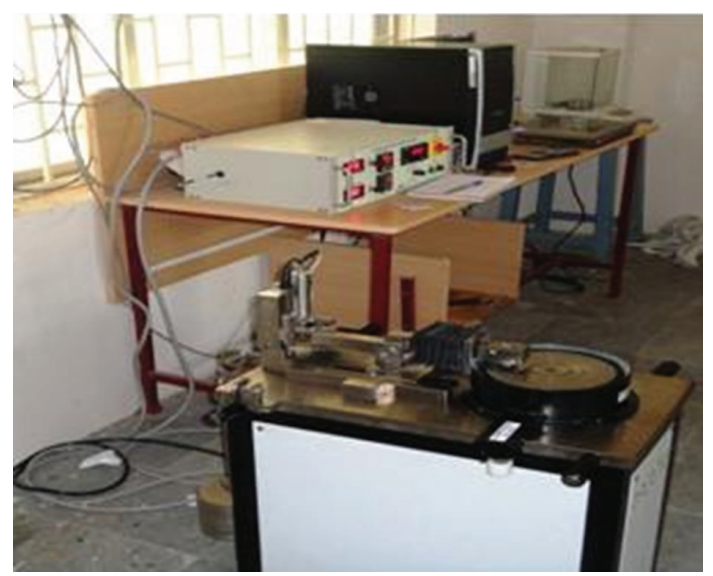

Figure 3: Pin-on-disc machine.

of EN-32 steel with the hardness of 65 HRC. At the end of each test, the weight loss of the specimen was noticed. The results obtained during this work have been presented in terms of sliding wear, specific wear rate, and friction coefficient. Sliding wear is related to interactions between surfaces and more specifically the removal and deformation of material on a surface as a result of mechanical action of the opposite surface. Specific wear rate is the volume loss per sliding distance and load. Friction coefficient is the ratio of the force of friction between two bodies and the force pressing them together.

2.4. Selection of Testing Parameters and Their Levels. The application of design-of-experiments (DoE) requires careful planning, prudent layout of the experiment, and expert analysis of results. Taguchi has standardized methods for each of these DoE application steps. The experiment specifies three principle wear testing conditions including applied load $(A)$, sliding speed $(B)$, and percentage of fly ash $(C)$ as the process parameters. The experiments were carried out to analyze the influence of sliding wear, specific wear rate and friction coefficient on the MMCs. Control factors and their levels are shown in Table 2. This table shows that the experimental plan had three levels.

The standard Taguchi experimental plan with notation $\mathrm{L}_{9}(3)^{4}$ was chosen based upon the degree of freedom. The degrees of freedom for the orthogonal array should be greater 
TABLE 2: Control factors and their levels.

\begin{tabular}{lcccc}
\hline Symbols & Design parameters & Level 1 & Level 2 & Level 3 \\
\hline$A$ & Applied load, N & 9.81 & 19.62 & 29.43 \\
$B$ & Sliding speed, m/s & 1 & 2 & 3 \\
$C$ & Percentage of fly ash, wt.\% & 5 & 10 & 15 \\
\hline
\end{tabular}

TABLE 3: $\mathrm{L}_{9}(3)^{4}$ orthogonal array.

\begin{tabular}{lccc}
\hline \multicolumn{3}{c}{ Control factors } \\
Ex. & $A$ & $B$ & $C$ \\
\hline 1 & 9.81 & 1 & 5 \\
2 & 9.81 & 2 & 10 \\
3 & 9.81 & 3 & 15 \\
4 & 19.62 & 1 & 10 \\
5 & 19.62 & 2 & 15 \\
6 & 19.62 & 3 & 5 \\
7 & 29.43 & 1 & 15 \\
8 & 29.43 & 2 & 5 \\
9 & 29.43 & 3 & 10 \\
\hline
\end{tabular}

than or at least equal to those of the process parameters. Table 3 shows the $\mathrm{L}_{9}(3)^{4}$ orthogonal array.

2.5. Experimental Details. The experimental results are transformed into a signal-to-noise $(\mathrm{S} / \mathrm{N})$ ratio. The-lower-thebetter characteristics were selected for sliding wear, specific wear rate and friction coefficient due to the wear resistance of the tested samples. A pin-on-disc type of apparatus was employed to evaluate the wear characteristics at a constant sliding distance of $3000 \mathrm{~m}$. Table 4 shows the experimental results of sliding wear, specific wear rate, and friction coefficient and their $\mathrm{S} / \mathrm{N}$ ratios.

\section{Grey Relational Analysis}

3.1. Multiresponse Optimization Using Grey Relational Analysis. Taguchi method is designed to optimize single response characteristic. The-higher-the-better performance for one factor may affect the performance because another factor may demand the-lower-the-better characteristics. Hence, multiresponse optimization characteristics are complex. Here the Grey relational analysis optimization methodology for multiresponse optimization is performed with the following steps.

(i) Normalizing the experimental results.

(ii) Performing the Grey relational generating and calculating the Grey relational coefficient.

(iii) Calculating the Grey relational grade by averaging the Grey relational coefficient.

(iv) Performing statistical analysis of variance (ANOVA) for the input parameters with the Grey relational grade to find which parameter significantly affects the process.

(v) Selecting the optimal levels of process parameters. (vi) Conducting confirmation experiment and verifying the optimal process parameters setting.

In Grey relational analysis, the complex multiple response optimizations can be simplified into the optimization of a single response Grey relational grade.

3.2. Grey Relational Generation. In the grey relational analysis, when the range of the sequence is large or the standard value is enormous, the function of factors is neglected. However, if the factors goals and directions are different, the Grey relational analysis might also produce incorrect results. Therefore, one has to preprocess the data which are related to a group of sequences, which is called "Grey relational generation."

For the-lower-the-better quality characteristics data preprocessing is calculated by

$$
x_{i j}=\frac{\left(y_{i j}\right)_{\max }-y_{i j}}{\left(y_{i j}\right)_{\max }-\left(y_{i j}\right)_{\min }},
$$

where $y_{i j}$ is the $i$ th experimental results in the $j$ th experiment. Table 5 shows the preprocessed data results.

The grey relational coefficients of each performance characteristic are calculated in Table 6 using (2).

The grey relation coefficient is

$$
\gamma\left(x_{0 j}, x_{i j}\right)=\frac{\Delta_{\min }+\zeta \Delta_{\max }}{\Delta_{i j}+\zeta \Delta_{\max }}
$$

for $i=1,2, \ldots, m j=1,2, \ldots, n$. where

$$
\begin{gathered}
\Delta_{i j}=\left|x_{0 j}-x_{i j}\right|, \\
\Delta_{\text {min }}=\operatorname{Min}\left\{\Delta_{i j}, i=1,2, \ldots, m ; j=1,2, \ldots, n\right\}, \\
\Delta_{\max }=\operatorname{Max}\left\{\Delta_{i j}, i=1,2, \ldots, m ; j=1,2, \ldots, n\right\},
\end{gathered}
$$

$\zeta$ is the distinguishing coefficient, $\zeta \in[0,1]$.

3.3. Grey Relational Grade. Table 7 shows the influence of process parameters of Grey relational grade. The higher value of the Grey relational grade represents the stronger relational degree of the reference sequence and the given sequence.

The grey relational grade is obtained by

$$
\alpha_{j}=\frac{1}{m} \sum_{i=1}^{m} \delta_{i j}
$$

where $\alpha_{j}$ is the Grey relational grade for the $j$ th experiment and $m$ is the number of performance characteristics.

As a result, optimization of the complicated multiple performance characteristics can be converted into optimization of single grey relational grade. The higher Grey relational grade represents that the experimental result is closer to the ideal normalized value. 
TABLE 4: Experimental results of wear and friction coefficient and their $\mathrm{S} / \mathrm{N}$ ratios.

\begin{tabular}{|c|c|c|c|c|c|c|}
\hline \multirow[b]{2}{*}{ Ex. } & \multicolumn{3}{|c|}{ Experimental results } & \multicolumn{3}{|c|}{$\mathrm{S} / \mathrm{N}$ ratios } \\
\hline & $\begin{array}{l}\text { Sliding wear } \\
(\mu)\end{array}$ & $\begin{array}{l}\text { Specific wear rate } \\
\left(\mathrm{m}^{2} / \mathrm{N}\right) \times 10^{-15}\end{array}$ & Friction coefficient & $\begin{array}{l}\text { Sliding wear } \\
(\mathrm{dB})\end{array}$ & $\begin{array}{l}\text { Specific wear rate } \\
(\mathrm{dB})\end{array}$ & $\begin{array}{l}\text { Friction coefficient } \\
\qquad(\mathrm{dB})\end{array}$ \\
\hline 1 & 146 & 249.4 & 0.254 & -43.28 & -47.93 & 11.87 \\
\hline 2 & 104 & 237.123 & 0.560 & -40.34 & -47.49 & 5.02 \\
\hline 3 & 82 & 184.3 & 0.244 & -38.27 & -45.31 & 12.22 \\
\hline 4 & 261 & 237.123 & 0.198 & -48.33 & -47.49 & 14.03 \\
\hline 5 & 298 & 219.07 & 0.214 & -49.48 & -46.81 & 13.38 \\
\hline 6 & 160 & 181.3 & 0.147 & -44.08 & -45.16 & 16.60 \\
\hline 7 & 369 & 228.93 & 0.383 & -51.34 & -47.19 & 8.31 \\
\hline 8 & 384 & 290.4 & 0.217 & -51.68 & -49.25 & 13.25 \\
\hline 9 & 414 & 323.48 & 0.224 & -52.34 & -50.19 & 12.98 \\
\hline
\end{tabular}

TABLE 5: Preprocessed data results.

\begin{tabular}{cccc}
\hline Ex. & $\begin{array}{c}\text { Sliding wear } \\
(\mu)\end{array}$ & $\begin{array}{c}\text { Specific wear rate } \\
\left(\mathrm{m}^{2} / \mathrm{N}\right) \times 10^{-15}\end{array}$ & Friction coefficient \\
\hline 1 & 0.807 & 0.521 & 0.741 \\
2 & 0.934 & 0.607 & 0.000 \\
3 & 1.000 & 0.979 & 0.765 \\
4 & 0.461 & 0.607 & 0.877 \\
5 & 0.349 & 0.734 & 0.840 \\
6 & 0.765 & 1.000 & 1.000 \\
7 & 0.136 & 0.665 & 0.428 \\
8 & 0.090 & 0.233 & 0.831 \\
9 & 0.000 & 0.000 & 0.815 \\
\hline
\end{tabular}

TABLE 6: Grey relational coefficient of each performance characteristic.

\begin{tabular}{lccc}
\hline Ex. & $\begin{array}{c}\text { Sliding wear } \\
(\mu)\end{array}$ & $\begin{array}{c}\text { Specific wear rate } \\
\left(\mathrm{m}^{2} / \mathrm{N}\right) \times 10^{-15}\end{array}$ & Friction coefficient \\
\hline 1 & 0.722 & 0.511 & 0.659 \\
2 & 0.883 & 0.560 & 0.333 \\
3 & 1.000 & 0.960 & 0.681 \\
4 & 0.481 & 0.560 & 0.802 \\
5 & 0.435 & 0.653 & 0.757 \\
6 & 0.680 & 1.000 & 1.000 \\
7 & 0.366 & 0.599 & 0.466 \\
8 & 0.355 & 0.395 & 0.748 \\
9 & 0.333 & 0.333 & 0.730 \\
\hline
\end{tabular}

\section{Wear Mechanism}

The typical wear mechanism of composites is presented in this section. At lower loads the sliding wear, specific wear rate, and friction coefficient decrease with increase in fly ash percentage, but as the load increases, they tend to increase with increase in fly ash percentage. The composites were also noticed to have mild wear as the sliding speed increases. The results were related and verified to the tests conducted by various researches $[21,22]$.
TABLE 7: Influence of process parameters of Grey relational grade.

\begin{tabular}{lcc}
\hline Ex. & Grey relational grade & Order \\
\hline 1 & 0.630 & 3 \\
2 & 0.592 & 6 \\
3 & 0.880 & 2 \\
4 & 0.614 & 5 \\
5 & 0.615 & 4 \\
6 & 0.893 & 1 \\
7 & 0.477 & 8 \\
8 & 0.499 & 7 \\
9 & 0.465 & 9 \\
\hline
\end{tabular}

TABLE 8: Response table for Grey relational grade.

\begin{tabular}{lcccc}
\hline \multirow{2}{*}{ Symbols } & \multicolumn{4}{c}{ Response table } \\
& Level 1 & Level 2 & Level 3 & Max-Min \\
\hline$A$ & 0.701 & 0.708 & 0.481 & 0.227 \\
$B$ & 0.574 & 0.569 & 0.746 & 0.178 \\
$C$ & 0.674 & 0.557 & 0.657 & 0.117 \\
Error & 0.570 & 0.654 & 0.664 & 0.094 \\
& Mean value of Grey relational grade $=0.629$ \\
\hline
\end{tabular}

Examinations of the worn surfaces of the composites were done by scanning electron microscope. Figure 4(a) shows the worn surface of the AA-6351-flyash composite (@19.62 N, $3 \mathrm{~m} / \mathrm{s}$, and $5 \mathrm{wt} . \%$ flyash), featuring some shallow grooves that are produced when there is abrasion in the tribological pair. Figure 4(b) shows the worn surface of AA 6351-flyash composite (@29.43 N, 1 m/s and 15 wt.\% flyash), featuring some shallow grooves and damages. Among the experiments conducted there was no seizure condition noticed.

\section{Analysis of Variance}

The analysis of variance (ANOVA) is used to investigate which design parameters significantly affect the quality characteristic. The traditional statistical technique can only obtain 
TABLE 9: Results of analysis of variance.

\begin{tabular}{lccccc}
\hline Design parameters & Degree of freedom (DOF) & Sum of squares (SS) & Mean of square (MS) & $F$-test & Contribution (\%) \\
\hline Applied Load, N & 2 & 0.100 & 0.050 & 6.25 & $49.71 \%$ \\
Sliding speed, m/s & 2 & 0.061 & 0.031 & 3.88 & $30.43 \%$ \\
Percentage of fly ash, \% & 2 & 0.024 & 0.012 & 1.50 & $11.89 \%$ \\
Error & 2 & 0.016 & 0.008 & & $7.97 \%$ \\
\hline Total & 8 & 0.201 & & $100.00 \%$ \\
\hline
\end{tabular}

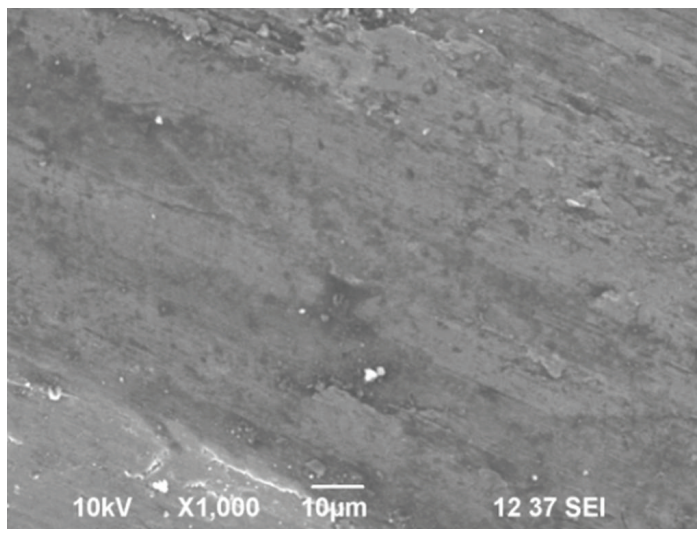

(a)

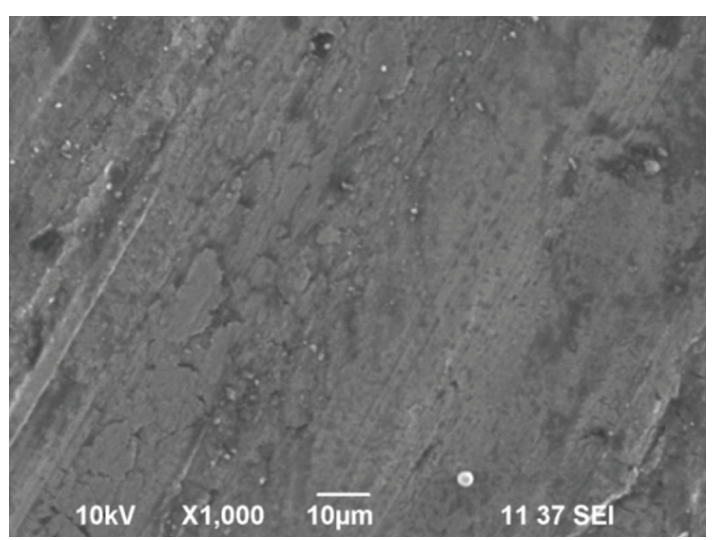

(b)

FIGURE 4: (a) SEM of worn surface with grooves. (b) SEM of worn surface with grooves and damages.

TABLE 10: Results of the confirmation experiment.

\begin{tabular}{lccc}
\hline \multirow{2}{*}{ Initial design parameters } & & \multicolumn{2}{c}{ Optimal design parameters } \\
& & Predicted & Experimental \\
\hline Level & A1B1C1 & A2B3C1 & A2B3C1 \\
Grey relational grade & 0.630 & 0.870 & 0.893 \\
Improvement in grade & - & 0.240 & 0.263 \\
\hline
\end{tabular}

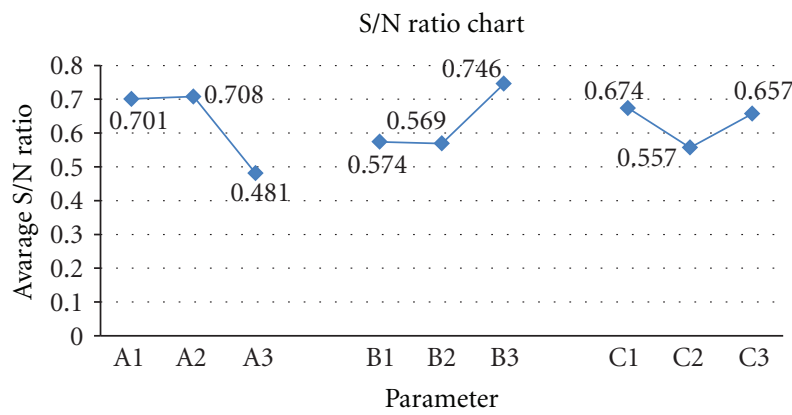

FIGURE 5: Main effects plot for $\mathrm{S} / \mathrm{N}$ ratios (dB).

one parameter in a single sequence; one has to do the analysis repeatedly to obtain other factors for the experiment.

Since the experimental design is orthogonal, it is then possible to separate the effects of each process parameter at different levels. For example, the mean of grey relational grade for the applied load at level 1, 2, and 3 can be calculated by taking the average of the grey relational grade for the experiments $1-3,4-6$, and 7-9, respectively. The mean of the grey relational grade for each level can be computed in similar manner. The mean of the grey relational grade for each level of the combining parameters is summarized in the multiresponse performance which is shown in Table 8. Figure 5 shows the main effects plot for $S / N$ ratios $(d B)$.

ANOVA of the response quality characteristics is shown in Table 9, and it is observed that applied load is the significant factor for minimizing the sliding wear, specific wear rate, and friction coefficient.

\section{Confirmation Tests}

The final step is to verify the improvement of the quality characteristic using optimal levels of the design parameters (A2B3C1). Table 10 shows a comparison of the predicted and the actual design parameters. According to Table 10, the improvement of the performance is noticed when the optimum conditions were used.

\section{Conclusions}

(i) Aluminum matrix reinforced with 5, 10, and $15 \mathrm{wt} . \%$ fly ash was successfully prepared by stir-casting process, and the wear behavior of the composites was investigated using pin-on-disc machine.

(ii) The $\mathrm{L}_{9}(3)^{4}$ orthogonal array was adopted to investigate the effects of operating variables on the abrasive wear of various composites.

(iii) The experimental results show that the composites retain the wear resistance properties at lower loads 
with increase in flyash percentage. Mild wear was also observed in the composites as the sliding speed increases.

(iv) For all the trials it is observed that mild-to-severe wear exists, and it is witnessed by the microscopic results.

(v) The applied load and sliding speed are the most influencing factors, and it is observed that their contributions to wear behavior are $49.71 \%$ and $30.43 \%$, respectively.

(vi) The optimum design parameters were predicted through Grey relational analysis (applied load = $19.62 \mathrm{~N}$, sliding speed $=3 \mathrm{~m} / \mathrm{s}$, and percentage of flyash $=5$ wt. $\%)$.

(vii) The confirmation experiment is conducted with the level A2B3C1 to verify the optimal design parameter, and it exhibits better wear performance.

\section{References}

[1] Y. Sahin, "Optimization of testing parameters on the wear behaviour of metal matrix composites based on the Taguchi method," Materials Science and Engineering A, vol. 408, no. 1-2, pp. 1-8, 2005.

[2] Y. Sahin, "Wear behaviour of aluminium alloy and its composites reinforced by $\mathrm{SiC}$ particles using statistical analysis," Materials and Design, vol. 24, no. 2, pp. 95-103, 2003.

[3] M. K. Surappa, S. V. Prasad, and P. K. Rohatgi, "Wear and abrasion of cast Al-Alumina particle composites," Wear, vol. 77, no. 3, pp. 295-302, 1982.

[4] C. Thiagarajan, R. Sivaramakrishnan, and S. Somasundaram, "Cylindrical grinding of SiC particles reinforced Aluminum Metal Matrix composites," ARPN Journal of Engineering and Applied Sciences, vol. 6, pp. 14-20, 2011.

[5] K. Kalaiselvan, N. Muruganand, and P. Siva, "Prod. and characterization of AA6061- $\mathrm{B}_{4} \mathrm{C}$ stir cast composite," Materials and Design, vol. 32, pp. 4004-4009, 2011.

[6] Y. Sahin and K. Özdin, "A model for the abrasive wear behaviour of aluminium based composites," Materials and Design, vol. 29, no. 3, pp. 728-733, 2008.

[7] A. T. Alpas and J. Zhang, "Effect of SiC particulate reinforcement on the dry sliding wear of aluminium-silicon alloys (A356)," Wear, vol. 155, no. 1, pp. 83-104, 1992.

[8] O. Yilmaz and S. Buytoz, "Abrasive wear of $\mathrm{Al}_{2} \mathrm{O}_{3}$-reinforced aluminium-based MMCs," Composites Science and Technology, vol. 61, no. 16, pp. 2381-2392, 2001.

[9] D. Mandal, B. K. Dutta, and S. C. Panigrahi, "Dry sliding wear behavior of stir cast aluminium base short steel fiber reinforced composites," Journal of Materials Science, vol. 42, no. 7, pp. 2417-2425, 2007.

[10] P. K. Rohatgi, B. F. Schultz, A. Daoud, and W. W. Zhang, "Tribological performance of A206 aluminum alloy containing silica sand particles," Tribology International, vol. 43, no. 1-2, pp. 455-466, 2010.

[11] B. K. Prasad, S. V. Prasad, and A. A. Das, "Abrasion-induced microstructural changes and material removal mechanisms in squeeze-cast aluminium alloy-silicon carbide composites," Journal of Materials Science, vol. 27, no. 16, pp. 4489-4494, 1992.
[12] B. N. P. Bai, B. S. Ramasesh, and M. K. Surappa, "Dry sliding wear of A356-Al-SiCp composites," Wear, vol. 157, no. 2, pp. 295-304, 1992.

[13] K. J. Bhansali and R. Mehrabian, "Abrasive wear of aluminummatrix composites," Journal of Metals, vol. 34, no. 9, pp. 30-34, 1982.

[14] C. S. Lee, Y. H. Kim, K. S. Han, and T. Lim, "Wear behaviour of aluminium matrix composite materials," Journal of Materials Science, vol. 27, no. 3, pp. 793-800, 1992.

[15] A. P. Sannino and H. J. Rack, "Dry sliding wear of discontinuously reinforced aluminum composites: review and discussion," Wear, vol. 189, no. 1-2, pp. 1-19, 1995.

[16] Sudarshan and M. K. Surappa, "Dry sliding wear of fly ash particle reinforced A356 Al composites," Wear, vol. 265, no. 3-4, pp. 349-360, 2008.

[17] Sudarshan and M. K. Surappa, "Synthesis of fly ash particle reinforced A356 Al composites and their characterization," Materials Science and Engineering A, vol. 480, no. 1-2, pp. 117-124, 2008.

[18] H. K. Durmuş, E. Özkaya, and C. Meriç, “The use of neural networks for the prediction of wear loss and surface roughness of AA 6351 aluminium alloy," Materials and Design, vol. 27, no. 2, pp. 156-159, 2006.

[19] W. Zhou and Z. M. Xu, "Casting of SiC reinforced metal matrix composites," Journal of Materials Processing Technology, vol. 63, no. 1-3, pp. 358-363, 1997.

[20] A. R. Ahamed, P. Asokan, and S. Aravindan, "EDM of hybrid Al-SiCp-B4Cp and Al-SiC p-Glassp MMCs," International Journal of Advanced Manufacturing Technology, vol. 44, no. 5-6, pp. 520-528, 2009.

[21] M. Ramachandra and K. Radhakrishna, "Effect of reinforcement of flyash on sliding wear, slurry erosive wear and corrosive behavior of aluminium matrix composite," Wear, vol. 262, no. 11-12, pp. 1450-1462, 2007.

[22] P. Shanmughasundaram, R. Subramanian, and G. Prabhu, "Some studies on aluminium-flyash composites fabricated by two step stir casting method," European Journal of Scientific Research, vol. 63, pp. 204-218, 2011. 

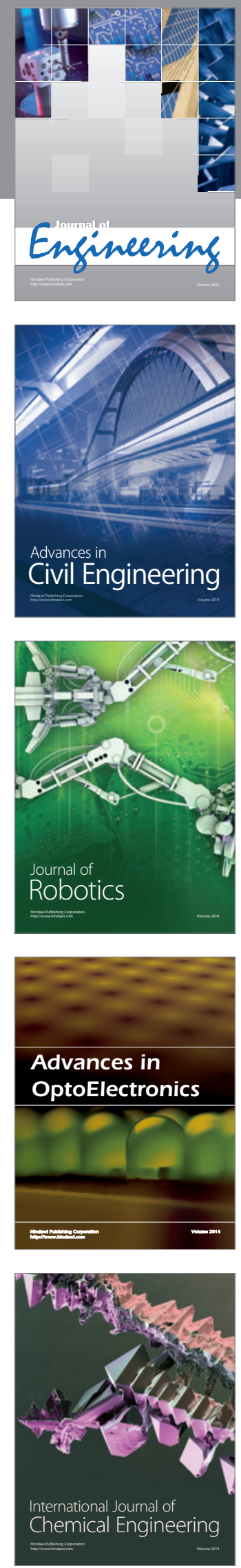

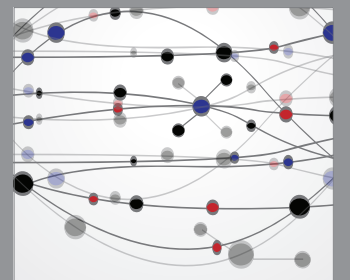

The Scientific World Journal
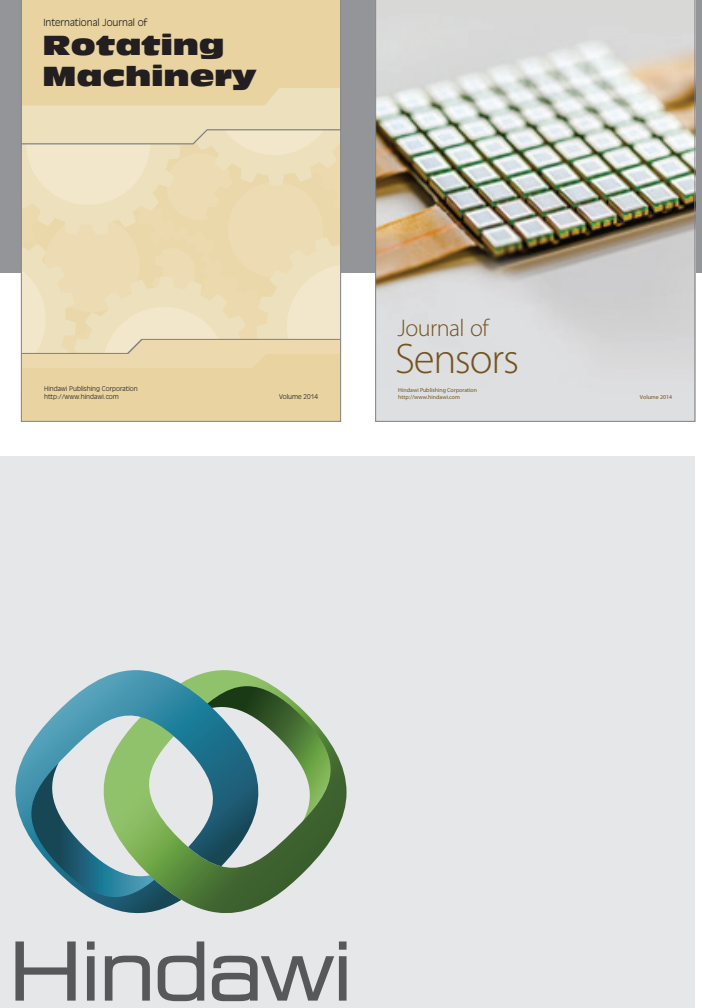

Submit your manuscripts at http://www.hindawi.com
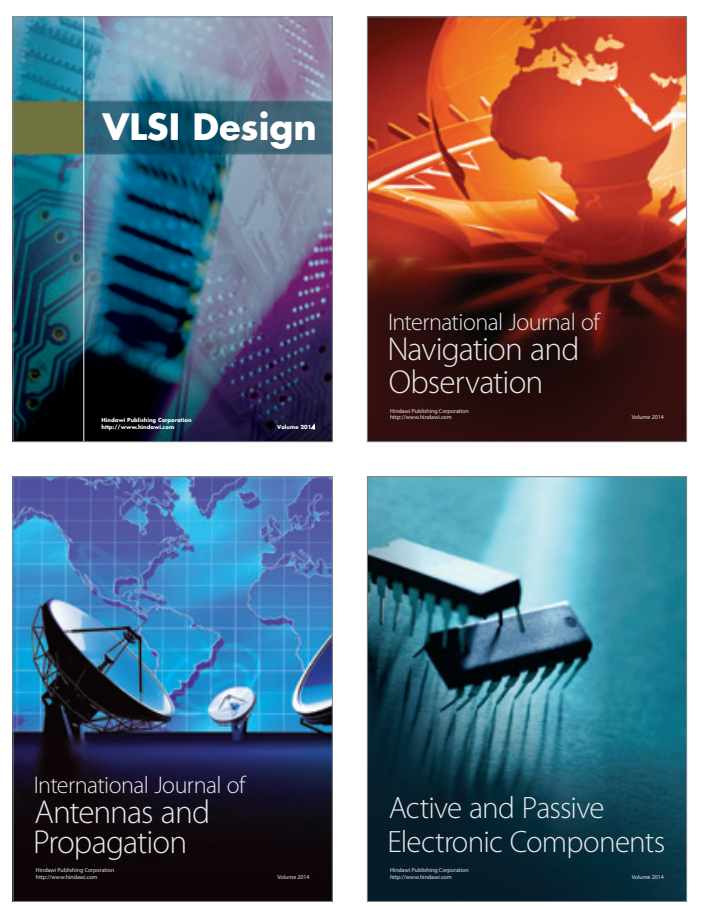
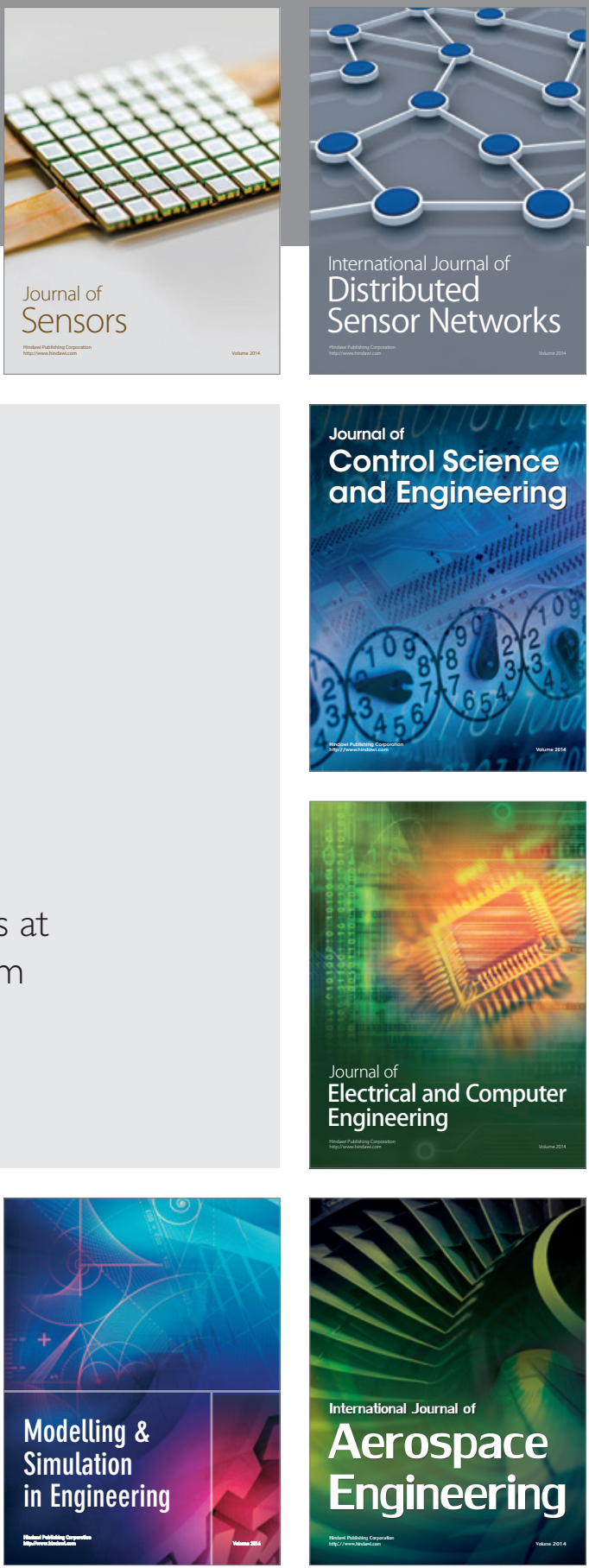

Journal of

Control Science

and Engineering
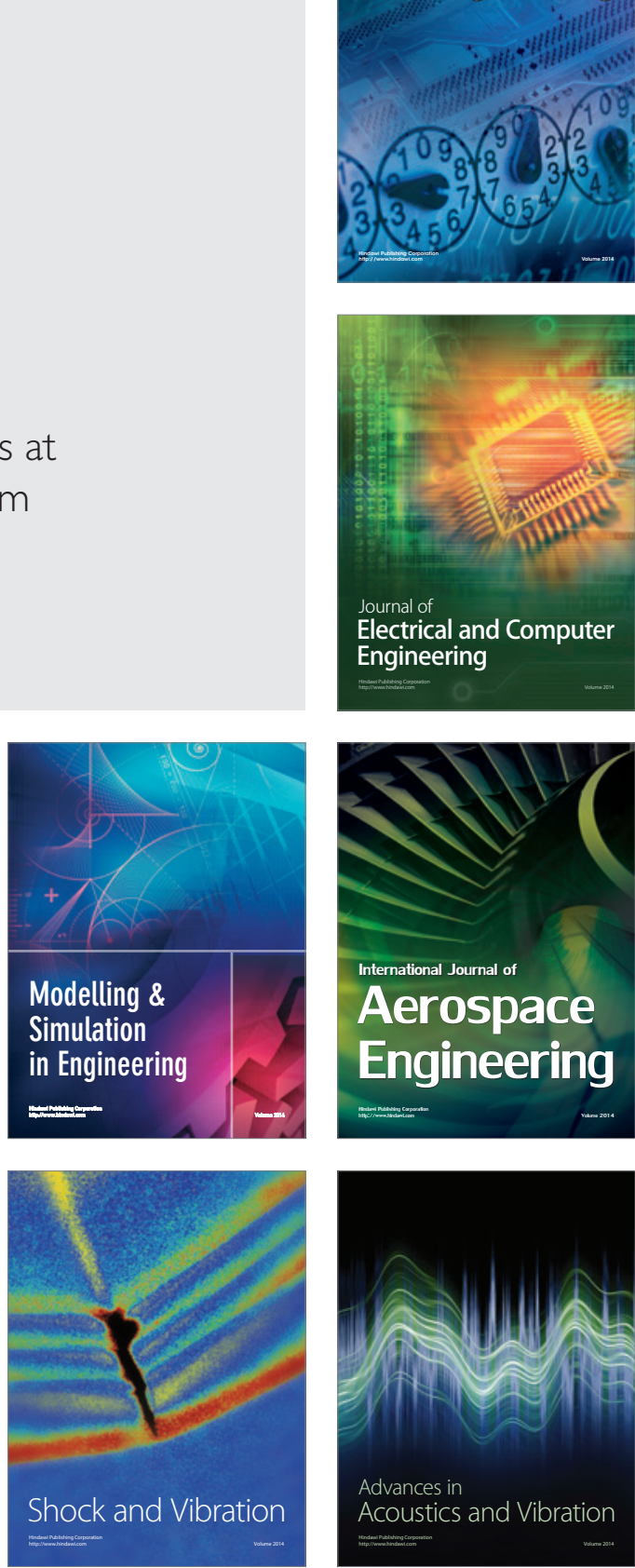